\title{
Can membrane progesterone receptor $\alpha$ on T regulatory cells explain the ensuing human labour?
}

\author{
Ana Areia ${ }^{a, b}, *$, Sofia Vale-Pereira ${ }^{b}$, Vera Alves $^{b}$, Paulo Rodrigues-Santos ${ }^{b}$, \\ Manuel Santos-Rosa ${ }^{b}$, Paulo Moura ${ }^{a, b}$, Anabela Mota-Pinto ${ }^{b}$ \\ a Obstetric Unit, Coimbra University Hospital Centre, Portugal \\ ${ }^{\mathrm{b}}$ Faculty of Medicine, University of Coimbra, Portugal
}

\section{A R T I C L E I N F O}

\section{Article history:}

Received 12 May 2015

Received in revised form

15 September 2015

Accepted 14 October 2015

\section{Keywords:}

Keywords

Labour

Progesterone

$\mathrm{mPR} \alpha$

Tregs

Pregnancy

\begin{abstract}
A B S T R A C T
Progesterone acts as an immunosteroid by contributing to the establishment of a pregnancy-protective milieu. It seems that it is the responsibility of progesterone to evade the inflammatory events that lead to parturition. T regulatory lymphocytes (Treg cells) could further explain the inhibition of the inflammatory mechanisms that lead to labour through the rapid action of progesterone on this cell subset. We investigated Treg cells and the membrane progesterone receptor $\alpha(\mathrm{mPR} \alpha)$ in these immune cells with in relationship to human parturition. This pilot cohort study was conducted in a single-centre tertiary obstetrical unit with 20 normal pregnant women. Variation in the absolute and relative frequency of $\mathrm{CD}^{+} \mathrm{T}$ cells, Treg cells, and of $\mathrm{mPR}^{\alpha+}$ Treg cells was calculated by flow cytometry on three occasions (second and third trimesters; delivery day). Our results show that during normal pregnancy there is a generalised increase in Treg cells and $\mathrm{mPR}^{\alpha+}$ Treg cells, from the second to the third trimesters $(23.4 \% \mathrm{vs}$. $52.3 \%$ and $4.3 \%$ vs. $8.3 \%$, respectively). On the contrary, on delivery day, compared with the values in the third trimester, there is a sudden decrease in both Treg cells $(52.3 \%$ vs. $17.4 \%)$ and $\mathrm{mPR}^{\alpha+}$ Treg cells $(8.3 \%$ vs. 6.1\%). Our findings suggest that human labour may develop as a consequence of a decline in $\mathrm{mPR}^{\alpha+}$ Treg cells, which reduces progesterone anti-inflammatory action through Treg cells.
\end{abstract}

(C) 2015 Elsevier Ireland Ltd. All rights reserved.

\section{Introduction}

In human species, contrary to other mammals, serum progesterone levels steadily increase throughout pregnancy, without any decline on delivery day, postulating the existence of a special mechanism for determining the timing of human labour (Byrns, 2014). Some of the mechanisms that have been proposed include changes in progesterone metabolism within target tissues and changes in progesterone receptor isoforms. Hence, an insufficient level of progesterone ligands in target tissues appears to be a determining factor for human parturition, despite the high levels of circulating progesterone (Byrns, 2014).

Implantation and parturition are specifically characterised by mechanisms of local inflammatory activity, with an influx of immune cells into the decidua to promote the recrudescence of an inflammatory process (Norman et al., 2007; Van Mourik et al., 2009; Thaxton et al., 2010). Accordingly, it is commonly accepted

* Corresponding author at: Rua Miguel Torga, 3030-165 Coimbra, Portugal. Fax: +351239481227.

E-mail address: analuisareia@gmail.com (A. Areia). that the act of giving birth is the final step in a proinflammatory signalling cascade that is orchestrated by an intrauterine milieu coupled with hormonal cues, both in term and preterm deliveries (Thaxton et al., 2010).

Progesterone plays a central role in the establishment and maintenance of human pregnancy, exerting its effects by binding and activating progesterone receptors (Zachariades et al., 2012). It appears to be the responsibility of progesterone to contain the inflammatory events that lead to parturition, such as cervical ripening, rupture of membranes and uterine contractions (Byrns, 2014). Additionally, the immunosuppressive effects of progesterone have been well described and several rapid, non-genomic actions of progesterone on lymphocytes have been reported (Ndiaye et al., 2012).

$\mathrm{T}$ regulatory (Treg) lymphocytes constitute about $5 \%$ of the peripheral $\mathrm{CD}^{+} \mathrm{T}$-cell population and are recognised as a major cell subset at peripheral immune tolerance, having a suppressive effect on inflammatory responses (Leber et al., 2010). In fact, the properties and behaviour of Treg cells confer on them the capacity to perform unique functions in the events of reproduction and pregnancy (Guerin et al., 2009).

Progesterone is a crucial hormone in the female reproductive tract (Polese et al., 2014) whose actions on T cells are still under 
dispute (Lee et al., 2012), though the association between Treg cells and progesterone levels has been confirmed during human pregnancy. In fact, progesterone increases not only the proportion of Treg cells, but also their suppressive capacity (Mjosberg et al., 2009; Mao et al., 2010; Weinberg et al., 2011).

Moreover, membrane progesterone receptors (mPR) are expressed in high levels in human peripheral blood T lymphocytes, and their levels seem to change in labour (Dressing et al., 2011; Ndiaye et al., 2012). These receptors may be responsible for the rapid non-genomic actions of cellular activation carried out by progesterone (Zhu et al., 2008, Dressing et al., 2011), the interaction of progesterone with the immune system (Larsen and Hwang, 2011) and therefore parturition.

The most thoroughly studied $\mathrm{mPR}, \mathrm{mPR} \alpha$, is downregulated in term and preterm labour (Fernandes et al., 2005). Accordingly, $\mathrm{mPR} \alpha$ constitutes an appropriate target for explaining the connection of progesterone to Treg cells, and their subsequent actions on labour. We investigated the role of $\mathrm{mPR} \alpha$ in the association of progesterone and immune cells with human parturition.

\section{Materials and methods}

\subsection{Population}

We undertook a pilot study consisting of a cohort of 20 normal pregnant women attending prenatal appointments at our Obstetrics Unit, from December 2013 to December 2014.

Inclusion criteria consisted of healthy pregnant women without pre-existing diseases attending normal prenatal appointments at our unit and with singleton pregnancies and first prenatal appointment before the $14^{\text {th }}$ week of gestation. Gestational age was assessed by first-trimester ultrasound.

Peripheral blood samples were obtained on three occasions: in the second trimester (14-28 weeks); third trimester ( $>28$ weeks) and on the day of delivery (immediately before delivery). The Ethical Committees of the Faculty of Medicine of the University of Coimbra (registration number CE-151/2011; issued in 31/01/2012) and of the Coimbra University Hospital (registration number CHUC008-12; issued in 02/05/2013) approved the investigation, and informed consent was obtained from each participant.

\subsection{Specimen collection}

Peripheral venous blood samples were obtained and collected in lithium heparin tubes. Samples were kept in a cool environment until they were processed, within one hour of collection, whenever possible.

\subsection{Flow cytometry}

In brief, $100 \mu \mathrm{L}$ of whole blood containing $0.5-1 \times 10^{6}$ white blood cells were placed in an appropriate test tube and stained to localise the $m P R \alpha$ receptor on the cell surface, using the $\mathrm{N}$-terminal $\mathrm{mPR} \alpha$ antibody as described by Thomas et al. (2007). Cells were first incubated in a blocking solution ( $0.5 \%$ bovine serum albumin in phosphate-buffered saline solution) for 30-60 min and then incubated with the mPR $\alpha$ antibody (Santa Cruz Biotechnology, Dallas, TX, USA) at room temperature for a further 30-60 min. Cells were washed with $0.5 \%$ bovine serum albumin in phosphate-buffered saline and incubated for $30 \mathrm{~min}$ with Cruz Fluor 488 goat anti-rabbit IgG secondary antibody (Santa Cruz Biotechnology), at room temperature in the dark. Cells were washed with a $0.5 \%$ bovine serum albumin solution in phosphate-buffered saline, and the surface was stained with PB-conjugated anti-CD4, PE-Cy7-conjugated antiCD25 and PerCP-Cy5.5-conjugated anti-CD127 (Biolegend, San Diego, CA, USA). The intracellular staining for Foxp3 detection was done using the staining set from eBioscience (San Diego, CA, USA) and AF647-labelled anti-human Foxp3 (Biolegend), following the manufacturer's instructions.

Flow cytometry data were acquired on a FACS Canto II instrument (BD Biosciences, San Jose, CA, USA) equipped with three lasers to allow multicolour detection with different fluorophores, using FACS DIVA software (BD Biosciences). Lymphocyte populations were selected according to the scattering signal in the forward angle (FSC-A) and side angle (SSC-A), and at least 50,000 gated lymphocyte cells were detected for each sample. Dead cells were excluded by forward and side scatter characteristics and a FSC-A vs. FSC-H dot plot was used to discriminate doublets, detecting disparity between cell size and cell signal. Isotype control antibodies were used to help to assess the level of background staining, in addition to samples without staining and a single stain, for each antibody.

\subsection{Treg analysis and $m P R \alpha$ expression}

The regulatory $\mathrm{T}$-cell population was defined as being $\mathrm{CD}^{+} \mathrm{CD} 25^{\text {high }} \mathrm{CD} 127^{\text {low }} \mathrm{Foxp}^{+}$, although the literature varies when considering markers for the exact phenotype of a Treg cell population (Lastovicka, 2013). For the isolation of the specific lymphocyte population, $\mathrm{CD}^{+} \mathrm{T}$ cells were first gated and CD25 and CD127 expression was analysed. Therefore, gating strategies were employed to evaluate the percentage of Treg cells and the percentage of Treg cells positive for $\mathrm{mPR} \alpha$.

Our gating strategy for identifying the Treg population was based on a total lymphocyte gate based on FSC/side-scattered light (SSC) dot plot followed by doublet discrimination with an FSCA vs. FSC-H dot plot. Accordingly, CD4-positive cells were gated over SSC characteristics; depending on CD25 and CD127 expression, $\mathrm{CD} 4^{+}$cells were gated based on the expression of $\mathrm{CD} 25^{\text {high }}$ and $\mathrm{CD} 127^{\text {low }}$ markers and therefore the $\mathrm{CD} 4^{+} \mathrm{CD} 25^{\text {high }} \mathrm{CD} 127^{\text {low }}$ population was detected. We moved on to the $\mathrm{CD} 4^{+} \mathrm{CD} 25^{\text {high }} \mathrm{CD} 127^{\text {low }}$ population, and also searched for Foxp $3^{+}$cells. In the regulatory Tcell population, the $\mathrm{mPR}^{\alpha+}$ subset was identified and characterized by percentage.

FlowJo software (Tree Star Data Analysis Software, Ashland, OR, USA) was used for flow cytometry analysis. We also performed an absolute count of each population based on the number of lymphocytes present in the complete blood count.

\subsection{Statistical analysis}

Data were analysed using IBM $^{\circledR}$ SPSS statistics 21 software (IBM ${ }^{\circledR}$ Corporation, New York, NY, USA) and quantitative results are expressed as mean \pm standard deviation (SD) or median and interquartile range (IQR). For the comparative analysis among groups, one-way ANOVA was performed for comparison among three groups with Bonferroni correction among normal distributions, while in skewed distributions the Kruskal-Wallis test was performed. Statistical significance was considered for a two-sided $p$ value $<0.05$ and there were no missing values in our analysis.

\section{Results}

A total of 60 peripheral venous blood samples were collected in our population of 20 normal pregnant women. The mean age was $28.8 \pm 5.3$ years and $70 \%$ were nulliparas. Samples were also retrieved in the second trimester (mean gestational age of $20.6 \pm 1.5$ weeks), third trimester (mean gestational age of $31.8 \pm 2.2$ weeks) and on delivery day (mean gestational age of $39.2 \pm 1.97$ weeks). The data are summarised in Tables 1 and 2 and are represented in Fig. 1.

The results show that $\mathrm{CD} 4^{+} \mathrm{T}$ cells in the total lymphocytes had a significant decrease in the third trimester in comparison with 
Table 1

Clinical data.

\begin{tabular}{ll}
\hline Variable & Normal pregnancy \\
\hline Age (years) & \\
$\quad$ Mean \pm standard deviation & $28.8 \pm 5.3$ \\
$\quad($ Min-max) & $(20-37)$ \\
Gestational age (weeks) & \\
$\quad$ Mean \pm standard deviation & \\
- Second trimester & $20.6 \pm 1.5$ \\
- Third trimester & $31.8 \pm 2.2$ \\
- Delivery & $39.2 \pm 1.97$ \\
Caucasian ( $n$, proportion) & $18(90 \%)$ \\
Nullipara ( $n$, proportion) & $14(70 \%)$ \\
Previous preterm birth ( $n$, proportion) & $2(10 \%)$ \\
Tobacco use ( $n$, proportion) & $2(10 \%)$ \\
Medical complications $(n$, proportion) & $1(5 \%)$ \\
Baby birthweight (grams) & \\
$\quad$ Mean \pm standard deviation & $3253 \pm 456.7$ \\
$\quad$ (Min-max) & $(2020-4000)$ \\
\hline
\end{tabular}

a Gestational diabetes mellitus controlled with diet and physical exercise.

Table 2

Analysis of different blood T-cells populations among normal pregnancy.

\begin{tabular}{|c|c|c|c|c|}
\hline Blood populations & $\begin{array}{l}\text { Second } \\
\text { trimester }\end{array}$ & $\begin{array}{l}\text { Third } \\
\text { trimester }\end{array}$ & Delivery & $p$ \\
\hline \multicolumn{5}{|l|}{$\mathrm{CD}^{+}$percentage } \\
\hline \multicolumn{5}{|c|}{$\mathrm{CD}^{+}{ }^{+}$absolute number ${ }^{\mathrm{a}}$} \\
\hline - IQR & $450-1358$ & $134-964$ & $396-1363$ & \\
\hline \multicolumn{5}{|l|}{ Tregs ${ }^{\mathrm{b}}$ percentage } \\
\hline - IQR & $14.4-47.2$ & $31-86$ & $9.3-38$ & \\
\hline \multicolumn{5}{|c|}{ Tregs $^{\mathrm{b}}$ absolute number ${ }^{\mathrm{a}}$} \\
\hline - Median & 6.5 & 15.2 & 13.8 & $0.2^{* *}$ \\
\hline - IQR & $0.2-23$ & $2.8-33$ & $5.7-32.9$ & \\
\hline \multicolumn{5}{|c|}{ Tregs ${ }^{\mathrm{b}} \mathrm{mPR}^{\alpha+}$ percentage } \\
\hline - Median & 4.3 & 8.3 & 6.1 & $0.05^{* *}$ \\
\hline - IQR & $0-10$ & $4.4-90$ & $2.6-17.7$ & \\
\hline \multicolumn{5}{|c|}{ Tregs $^{\mathrm{b}} \mathrm{mPR}^{\alpha+}$ absolute number ${ }^{\mathrm{a}}$} \\
\hline - Median & 0.09 & 1.4 & 0.4 & $0.02^{* *}$ \\
\hline - IQR & $0-1.2$ & $0.9-2.8$ & $0.1-3.4$ & \\
\hline
\end{tabular}

Data are presented as mean and standard deviation (SD) and median with interquartile range (IQR).

* Significant mean difference between two groups at the 0.05 level using ANOVA (multiple comparisons using Bonferroni correction).

** Non-parametric tests (Kruskal-Wallis) with a significance level of 0.05 .

a Number cells/ $\mu$ l blood.

b Tregs: $\mathrm{CD} 4^{+} \mathrm{CD} 25^{\text {high }} \mathrm{CD} 127^{\text {low }}$ Foxp3 $3^{+}$.

the second trimester, both in percentage ( $32.7 \%$ vs. $44.8 \% ; p=0.04)$, and it absolute number ( 480 vs. 838 cells $/ \mu l ; p=0.2$ ). On the contrary, there was an increase in delivery day samples compared with the third trimester (from $32.7 \%$ to $44.1 \% ; p=0.2$ and from 480 to 670 cells $/ \mu \mathrm{l} ; p=0.2$ ).

The Treg cell population augmented from the second to the third trimester of pregnancy, both in terms of percentages $(23.4 \%$ vs. $52.3 \%$; $p=0.003$ ), and in terms of absolute number (6.5 vs.
15.2 cells $/ \mu \mathrm{l} ; p=0.2$ ). However, a statistically significant decrease in their percentage from the third trimester to delivery day samples could be perceived ( $52.3 \%$ vs. $17.4 \% ; p=0.003$ ).

As in the Treg cell population, the expression of $\mathrm{mPR}^{\alpha+}$ Treg cells at these three precise times of pregnancy also rose from the second to the third trimester $(4.3 \%$ vs. $8.3 \%$ and 0.09 vs. 1.4 cells $/ \mu \mathrm{l}$; $p=0.02$ ), with a decline in delivery day samples ( $8.3 \%$ vs. $6.1 \%$ and 1.4 vs. 0.4 cells $/ \mu \mathrm{l} ; p=0.02$ ).

\section{Discussion}

Progesterone withdrawal is a key event in the parturition process in all the species studied so far (Mesiano et al., 2011). The human species is exclusive because progesterone levels remain sustained during pregnancy and labour, which prompted several investigators to study the triggering of human labour. In fact, the prevailing theory postulates that human parturition involves functional, rather than systemic, progesterone withdrawal (Mesiano et al., 2011) and in a previous report, our group demonstrated the existence of $\mathrm{mPR} \alpha$ in the Treg cell pool throughout human pregnancy (Areia et al., 2015).

Our results demonstrated that in normal pregnancy there is a higher percentage and absolute number of Treg cells in the third trimester ( $52.3 \%$ and 15.2 cells $/ \mu \mathrm{l}$ ), followed by a corresponding protective role against maternal immune reactions and labour, as depicted in the literature (Xiong et al., 2010). Nevertheless, the variation in the number of Treg cells during the three trimesters of normal human pregnancy is still under debate, with some authors reporting a rise in the first trimester with a peak in the second trimester (Xiong et al., 2010), whilst others say there is a reduction in the second trimester (Saito et al., 2010; Teles et al., 2013). Moreover, our investigation observed a decline in Treg cells on the delivery date (to $17.4 \%$ and 13.8 cells $/ \mu \mathrm{l}$ ), confirming recent data that indicated a significant decrease in Treg cells expressing Foxp3 in women in labour at term and corroborating the fact that Treg cells seem to play a role in the immunological changes preceding labour (Guerin et al., 2009; Schober et al., 2012).

The present research also showed that the highest Treg cell $\mathrm{mPR}^{\alpha+}$ percentage and absolute number in normal pregnancy was obtained in the third trimester ( $8.3 \%$ and 1.4 cells/ $\mu$ l, respectively), with a decrease on delivery day, both in percentage ( $8.3 \%$ vs. $6.1 \%)$ and absolute number ( 1.4 vs. 0.4 cells $/ \mu \mathrm{l}$ ). Comparable to our findings, preceding investigations revealed that $\mathrm{mPR} \alpha$ messenger RNA reached a peak in mid-pregnancy, with a reduction at the end of pregnancy, warranting further investigation to confirm these results (Dressing et al., 2011).

Consequently, this research may provide possible clarification for the reduction in the anti-inflammatory action of progesterone, which prompts labour, despite normal systemic progesterone levels (functional withdrawal).

Some authors have indicated a significant decrease in $\mathrm{CD} 4^{+} \mathrm{T}$ cells within the total leukocyte pool during spontaneous labour, which could indicate that a strong immune stimulation and subsequent apoptosis of the activated $\mathrm{CD} 4^{+} \mathrm{T}$ cells may occur during that specific time (Schober et al., 2012). When comparing our results with those published in the literature, this population showed an increase on delivery day in relation to the third trimester (to $44.1 \% \pm 16.0 \%$ ), returning to levels similar to second-trimester values, in contrast to the published data. This may be explained by the fact that our measurements were undertaken before the alleged aforementioned apoptosis occurred. Thus, these findings underline the importance of further investigation to define the exact role of this population in order for labour to progress.

This is a piece of primary research concerning the variation of specific T-cell subsets at three defined obstetrical moments 

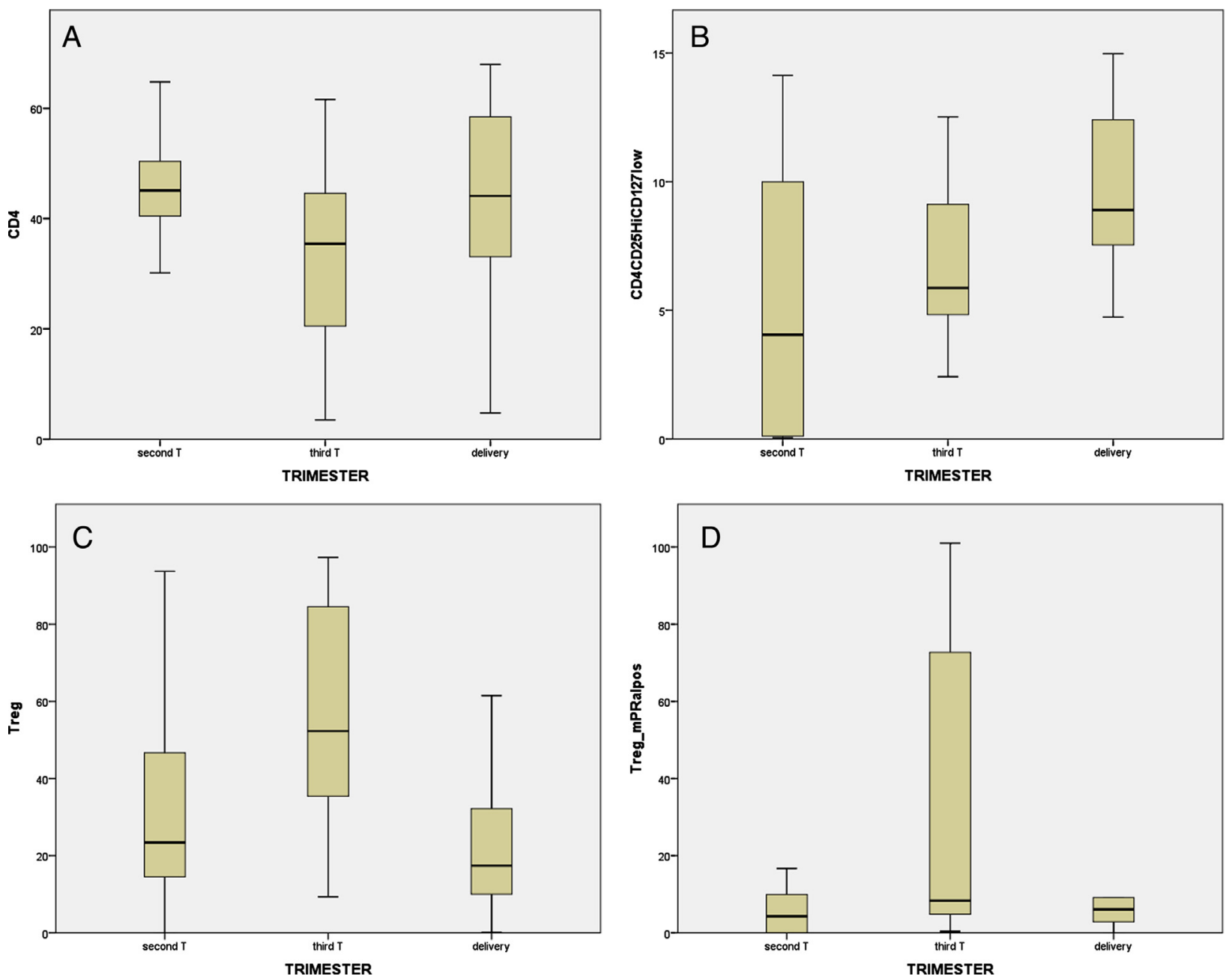

Fig. 1. Box plots representative of the percentage variation in the different blood populations studied in normal pregnancy.

T: Trimester. A: $\mathrm{CD}^{+}$percentage; B: $\mathrm{CD} 4^{+} \mathrm{CD} 25^{\text {high }} \mathrm{CD} 127^{\text {low }}$ percentage; C: Treg cells percentage; D: $\mathrm{mPR}^{\alpha+}$ Treg cells percentage.

(second trimester, third trimester and delivery day). From this initial approach, the fact that on delivery day all blood populations demonstrated completely different numbers from third-trimester values strengthens the theory of the existence of an immune triggering process that induces human labour.

Nevertheless, there are limitations in our study that need to be considered. The different antibody panel chosen to characterise our Treg cell population is controversial and the small sample size means that our conclusions should be inferred with caution, with the need for further investigation in this field with a higher number of pregnant women. Also, the corroboration of these results using other laboratory techniques, namely Western Blot and $R T-P C R$, is required.

In conclusion, this investigation suggests that normal human labour might be related to a reduction in $\mathrm{mPR}^{\alpha+}$ Treg cells, which reduces the probable anti-inflammatory action of progesterone through Treg cells, releasing the inflammatory cascade of cervical ripening, rupture of membranes and uterine contractions. This raises the possibility of the decline in progesterone receptor $\mathrm{mPR} \alpha$ as the reason for the functional withdrawal witnessed in term labour.

\section{Conflict of interest}

The authors report no conflict of interest.

\section{Acknowledgements}

This research was possible due to the assistance from the Office of Research Support, Faculty of Medicine, University of Coimbra, Portugal.

\section{References}

Areia, A., Vale-Pereira, S., Alves, V., Rodrigues-Santos, P., Moura, P., Mota-Pinto, A., 2015. Membrane progesterone receptors in human regulatory T cells: a reality in pregnancy. BJOG 122, 1544-1550.

Byrns, M.C., 2014. Regulation of progesterone signaling during pregnancy: implications for the use of progestins for the prevention of preterm birth. J. Steroid Biochem. Mol. Biol. 139, 173-181.

Dressing, G.E., Goldberg, J.E., Charles, N.J., Schwertfeger, K.L., Lange, C.A., 2011. Membrane progesterone receptor expression in mammalian tissues: a review of regulation and physiological implications. Steroids 76, 11-17.

Fernandes, M.S., Pierron, V., Michalovich, D., Astle, S., Thornton, S., Peltoketo, H., et al., 2005. Regulated expression of putative membrane progestin receptor homologues in human endometrium and gestational tissues. J. Endocrinol. 187, 89-101.

Guerin, L.R., Prins, J.R., Robertson, S.A., 2009. Regulatory T-cells and immune tolerance in pregnancy: a new target for infertility treatment? Hum. Reprod. Update 15, 517-535.

Larsen, B., Hwang, J., 2011. Progesterone interactions with the cervix: translational implications for term and preterm birth. Infect. Dis. Obstet. Gynecol. 2011, 353297.

Lastovicka, J., 2013. The phenotypic markers of CD4 + CD25 + T regulatory lymphocytes. Res. Immunol. 2013, 1-14.

Leber, A., Teles, A., Zenclussen, A.C., 2010. Regulatory T cells and their role in pregnancy. Am. J. Reprod. Immunol. 63, 445-459. 
Lee, J.H., Lydon, J.P., Kim, C.H., 2012. Progesterone suppresses the mTOR pathway and promotes generation of induced regulatory T cells with increased stability. Eur. J. Immunol. 42, 2683-2696.

Mao, G., Wang, J., Kang, Y., Tai, P., Wen, J., Zou, Q., et al., 2010. Progesterone increases systemic and local uterine proportions of CD4 + CD25+ Treg cells during midterm pregnancy in mice. Endocrinology 151, 5477-5488.

Mesiano, S., Wang, Y., Norwitz, E.R., 2011. Progesterone receptors in the human pregnancy uterus: do they hold the key to birth timing? Reprod. Sci. 18, 6-19.

Mjosberg, J., Svensson, J., Johansson, E., Hellstrom, L., Casas, R., Jenmalm, M.C., et al., 2009. Systemic reduction of functionally suppressive CD4dimCD25highFoxp3+ Tregs in human second trimester pregnancy is induced by progesterone and 17beta-estradiol. J. Immunol. 183, 759-769.

Ndiaye, K., Poole, D.H., Walusimbi, S., Cannon, M.J., Toyokawa, K., Maalouf, S.W., et al., 2012. Progesterone effects on lymphocytes may be mediated by membrane progesterone receptors. J. Reprod. Immunol. 95, 15-26.

Norman, J.E., Bollapragada, S., Yuan, M., Nelson, S.M., 2007. Inflammatory pathways in the mechanism of parturition. BMC Pregnancy Childbirth 7 (Suppl. 1), S7.

Polese, B., Gridelet, V., Araklioti, E., Martens, H., Perrier D’hauterive, S., Geenen, V. 2014. The endocrine milieu and CT4 T-lymphocyte polarization during pregnancy. Front. Endocrinol. 5, 106.

Saito, S., Nakashima, A., Shima, T., Ito, M., 2010. Th1/Th2/Th17 and regulatory T-cell paradigm in pregnancy. Am. J. Reprod. Immunol. 63, 601-610.

Schober, L., Radnai, D., Schmitt, E., Mahnke, K., Sohn, C., Steinborn, A., 2012. Term and preterm labor: decreased suppressive activity and changes in composition of the regulatory T-cell pool. Immunol. Cell Biol. 90, 935-944.
Teles, A., Thuere, C., Wafula, P.O., El-Mousleh, T., Zenclussen, M.L., Zenclussen, A.C. 2013. Origin of Foxp3(+) cells during pregnancy. Am. J. Clin. Exp. Immunol. 2, 222-233.

Thaxton, J.E., Nevers, T.A., Sharma, S., 2010. TLR-mediated preterm birth in response to pathogenic agents. Infect. Dis. Obstet. Gynecol. 2010, pii: 378472.

Thomas, P., Pang, Y., Dong, J., Groenen, P., Kelder, J., De Vlieg, J., et al., 2007. Steroid and $G$ protein binding characteristics of the seatrout and human progestin membrane receptor alpha subtypes and their evolutionary origins. Endocrinology 148, 705-718.

Van Mourik, M.S., Macklon, N.S., Heijnen, C.J., 2009. Embryonic implantation: cytokines, adhesion molecules, and immune cells in establishing an implantation environment. J. Leukoc. Biol. 85, 4-19.

Weinberg, A., Enomoto, L., Marcus, R., Canniff, J., 2011. Effect of menstrual cycle variation in female sex hormones on cellular immunity and regulation. J. Reprod. Immunol. 89, 70-77.

Xiong, H., Zhou, C., Qi, G., 2010. Proportional changes of CD4 + CD25 + Foxp3+ regulatory $\mathrm{T}$ cells in maternal peripheral blood during pregnancy and labor at term and preterm. Clin. Invest. Med. 33, E422.

Zachariades, E., Mparmpakas, D., Pang, Y., Rand-Weaver, M., Thomas, P., Karteris, E., 2012. Changes in placental progesterone receptors in term and preterm labour. Placenta 33, 367-372.

Zhu, Y., Hanna, R.N., Schaaf, M.J., Spaink, H.P., Thomas, P., 2008. Candidates for membrane progestin receptors-past approaches and future challenges. Comp. Biochem. Physiol. C Toxicol. Pharmacol. 148, 381-389. 